\title{
Figuras da psicologia francófona do final do século XIX
}

\author{
Figures of Francophone psychology from the late 19th century
}

Figuras de la psicología francófona de finales del siglo XIX

Les figures de la psychologie francophone de la fin du XIXe siècle

\author{
Yuri Pereira Antunes Vieira; André Elias Morelli Ribeiro
}

Universidade Federal Fluminense

\section{RESUMO:}

A expressão psicologia francófona designa uma série de saberes e práticas psicológicas que foram desenvolvidas em países cujo idioma principal é o francês, ou por autores que desenvolveram suas ideias neste idioma. Sua conceituação, apesar de bastante ampla, agrupa muitos atores que foram relevantes para a constituição da psicologia no Brasil, através de diversos meios. Contata-se, contudo, que poucos materiais em português foram publicados no Brasil após os anos 1950 sobre vários dos atores da psicologia francófona, de modo que permanecem, em diferentes graus, desconhecidos dos profissionais da psicologia e, muitas vezes, até mesmo dos historiadores. Este trabalho pretende auxiliar no preenchimento desta lacuna ao elaborar biografias de cinco autores francófonos do final do século XIX, importantes para a compreensão da psicologia brasileira: Paul Janet, Théodule Ribot, Henri Beaunis, Alfred Binet e Pierre Janet. Conclui-se que o conceito geral é bastante plural, de modo que as recepções e apropriações destes atores no Brasil ainda estão por ser melhor analisados.

Palavras-chave: História da psicologia, Psicologia Francófona, Psicologia na França

\section{ABSTRACT:}

The term Francophone psychology refers to a series of psychological knowledge and practices that were developed in countries whose main language is French, or by authors who developed their ideas in that language. Its conceptualization, although quite broad, groups many actors that were relevant to the constitution of psychology in Brazil, through various means. However, it is reported that only exists few materials in Portuguese published in Brazil after the 50's about several of those actors part of the Francophone psychology. So that they remain, in varying degrees, unknown to most psychology professionals and even to historians of psychology. This work aims to help fill this gap by presenting biographies of five French-speaking authors from the late 19th century who are important for understanding Brazilian psychology: Paul Janet, Théodule Ribot, Henri Beaunis, Alfred Binet and Pierre Janet. It is concluded that the general concept is quite plural, so that the receptions and appropriations of these actors in Brazil are yet to be better analyzed.

Key-words: History of Psychology, Francophone Psychology, Psychology in France 


\section{RESUMEN:}

El término psicología francófona se refiere a una serie de conocimientos y prácticas psicológicas que se han desarrollado en países cuyo idioma principal es el francés, o por autores que han desarrollado sus ideas en este idioma. Su conceptualización, aunque bastante amplia, reúne a muchos actores que han sido relevantes para la constitución de la psicología en Brasil, a través de diversos medios. Sin embargo, se informa de que en el Brasil se han publicado pocos materiales en portugués después de los años 1950 sobre varios de los actores de la psicología francófona, por lo que siguen siendo, en diversos grados, desconocidos para los profesionales de la psicología y a menudo incluso para los historiadores. Esta obra pretende contribuir a llenar este vacío mediante la elaboración de biografías de cinco autores francófonos de finales del siglo XIX importantes para la comprensión de la psicología brasileña: Paul Janet, Théodule Ribot, Henri Beaunis, Alfred Binet y Pierre Janet. Se concluye que el concepto general es bastante plural, por lo que las recepciones y apropiaciones de estos actores en Brasil aún deben ser mejor analizadas.

Palabras-clave: Historia de la Psicología, Psicología francófona, Psicología en Francia

\section{RÉSUMÉ:}

Le terme de psychologie francophone fait référence à une série de connaissances et de pratiques psychologiques qui ont été développées dans des pays dont la langue principale est le français, ou par des auteurs qui ont développé leurs idées dans cette langue. Sa conceptualisation, bien qu'assez large, regroupe de nombreux acteurs qui ont été pertinents pour la constitution de la psychologie au Brésil, par divers moyens. Cependant, il est signalé qu'il n'existe que peu de textes en portugais après les années 1950 publiés au Brésil sur plusieurs de ces acteurs qui faisant partie de la psychologie francophone. De sorte qu'ils restent, à des degrés divers, inconnus de la plupart des professionnels de la psychologie et même des historiens de la psychologie. Cet ouvrage vise aider à remplis cette lacune en présentant des biographies de cinq auteurs francophones de la fin du XIXe siècle qui sont importants pour la compréhension de la psychologie brésilienne : Paul Janet, Théodule Ribot, Henri Beaunis, Alfred Binet et Pierre Janet. Il est conclu que le concept général est assez pluriel, de sorte que les réceptions et les appropriations de ces acteurs au Brésil restent encore à mieux analyser.

Mots-clé: Histoire de la psychologie, psychologie francophone, psychologie en France

\section{Introdução}

A psicologia brasileira, ao longo de sua história, recepcionou e circulou diferentes versões de psicologias produzidas por falantes nativos de língua francesa (PAROT; RICHELLE, 1992). Estas versões de psicologia em francês podem ser denominadas genericamente como psicologia francófona. Sob esta rubrica são incluídos saberes e práticas psicológicas, como pensamentos, livros, ideias, conceitos e proposições intelectuais e acadêmicas originários de pensadores, médicos, filósofos, psicólogos, intelectuais, entre outros, que eram falantes nativos de francês, a tinham por língua principal ou formaram-se parcial ou 
integralmente em países como França, Suíça e a Bélgica. Estes saberes e práticas psi, longe de se organizarem em um único arranjo lógico e coerente, mostram-se múltiplos e baseados em diferentes modalidades de compreensão da psicologia, de modo que sua unidade está no idioma e o caldo cultural que as originam.

No Brasil, a chegada e circulação da psicologia francófona se mostrou múltipla e diversa, se devendo principalmente à penetração da cultura francesa entre os intelectuais brasileiros. Um primeiro exemplo pode ser encontrado dentro do movimento da Escola Nova (ANTUNES, 1999), que ingressou no Brasil majoritariamente por autores francófonos como Edouard Claparède e Adolphe Ferrière. O célebre fundador do Instituto Jean-Jacques Rousseau foi determinante para o pensamento e ação de Lourenço Filho, que traduziu várias obras do mestre genebrino e teve um papel fundamental na viabilização de sua visita ao Brasil (SILVA, 2013).

Outro exemplo é o de Waclaw Radecki, psicólogo polonês e diretor de um dos primeiros laboratórios de psicologia no Brasil. Apesar de não ser francófono de nascimento, foi formado sob esta tradição, obtendo seu título de doutorado em Genebra, uma das mais conhecidas representantes da psicologia francófona, sob a orientação de Claparède e Théodore Flournoy (CENTOFANTI, 1982). É semelhante o exemplo de Helena Antipoff, psicóloga russa essencial para a formação da psicologia brasileira e também aluna de Claparède (CAMPOS et al, 2004), além de ter sido estagiária no laboratório de psicologia e pedagogia experimental criado por Alfred Binet (CASSEMIRO; CAMPOS, 2019), outro representante da psicologia francófona.

Ainda na seara dos exemplos da relevância da psicologia francófona para o Brasil situase o movimento francês de avaliação da inteligência (ROTA-JÚNIOR et al, 2019). Manoel Bomfim, o fundador do primeiro laboratório de psicologia em terras brasileiras, estudou com Binet na Sorbonne em 1902, construindo um laboratório inspirado no do psicólogo francês (CAMPOS et al, 2004). É também de Binet um dos primeiros testes psicológicos utilizados amplamente em terras brasileiras, num movimento denominado psicologização do campo pedagógico (CAMPOS et al., 2014) e que rendeu publicações no Brasil de obras de Binet e outros psicólogos ligados a esta vertente.

Um quarto exemplo da relevância francesa na psicologia brasileira, apontado por Penna (1992), é a presença da psiquiatria francesa na constituição da psiquiatria nacional. Maurício de Medeiros fundou um laboratório construído sob influência de um psiquiatra francês, George Dumas (PENNA; MASIERO, 2001). Gouveia (2001) localiza entre psiquiatras brasileiros 
ideias de Bénédict Morel - nascido na Áustria mas incluído na psicologia francófona -, Philippe Pinel, Jean-Etienne-Dominique Esquirol, Étienne Georget, entre outros.

Um quinto exemplo foi sugerido por Vanconcelos (1996). Estudando a difusão das ideias de Piaget no Brasil, o autor anotou interessante fala de Graciema Pacheco, que afirmou, ainda nos anos 1930, sobre o desenvolvimento da psicologia e pedagogia no Brasil, que: "Naquela época, nós tínhamos muito interesse pelas coisas da França [...] nós nos interessamos pelas publicações francesas [...]" (VASCONCELOS, 1996, p.62), constituindo-se como mais um exemplo da importância das ideias em francês no país. Mesmo a chegada da psicanálise no Brasil se deu por autores francófonos que, curiosamente, a criticavam fortemente (OLIVEIRA, 2002).

Por fim, é relevante destacar que vieram da França tanto o primeiro catedrático de Psicologia da Universidade do Brasil, André Ombredane (FÁVERO, 1989), quanto Etienne Souriau, que ocupou uma cátedra de Psicologia e Filosofia na Universidade do Distrito Federal - depois Universidade do Brasil (PENNA, 2001) -, o que indica uma presença física na constituição e institucionalização da psicologia no país.

Os seis exemplos apresentados até agora não encerram a questão. Uma investigação na história da psicologia trará muitos outros exemplos da conexão existente entre nossa psicologia brasileira e a desta matriz específica, o que mostra a importância da psicologia francófona no nosso país. Além da psicologia, a relevância do pensamento deste tipo para o Brasil pode ser verificada em muitos outros espaços das ciências, artes e intelectualidade brasileira em geral. A Biblioteca Nacional, reconhecendo a importância da França para a formação do Brasil, como as missões francesas, a circulação de ideias, entre outros, dedica uma seção permanente ao tema, em colaboração com a Bibliothèque Nationale de France.

Apesar da relevância e presença da matriz francófona para a psicologia brasileira, não existem muitos trabalhos que dissertem sobre essa relação. Um dos primeiros pesquisadores a notar a relevância da matriz francófona para a constituição da psicologia brasileira foi Penna (1992). O autor afirma que tais pensadores eram os mais lidos nos estudos de psicologia empreendidos na cidade do Rio de Janeiro, na ocasião em que a cidade era a capital do país. Ele ainda destaca a relevância de alguns dos nomes da psicologia francesa na composição da psicologia brasileira, como Théodule Ribot, Alfred Binet, George Dumas, Pierre Janet, Henri Wallon, além dos suíços Jean Piaget e Édouard Claparède (PENNA, 1992). 
Outra pesquisadora a escrever sobre a importância dos francófonos é Mello (2017) que, em sua tese de doutoramento, defendida na École des Hautes Études en Sciences Sociales, tratou das missões científicas francesas no Brasil, no período de 1908 a 1947 (MELLO, 2017). Em seu trabalho, a autora conclui pela relevância dos autores e pensadores franceses no processo de modernização da intelectualidade e da educação superior no Brasil.

\section{A psicologia francesa nos manuais de história da psicologia publicados no Brasil}

Apesar da importância da matriz francesa, ela não é muito discutida nos manuais de estudos em história da psicologia publicados no Brasil. Esta falta, que não é total e tem uma notável exceção, sugere um desconhecimento geral desta relevante matriz entre estudantes e profissionais de psicologia, uma vez que os manuais, enquanto materiais introdutórios para o estudo psicológico, representam uma importante fonte para o processo de formação (GOMES; DA SILVA ALENCASTRO, 2011; KUHN, 1994).

Em uma análise dos manuais, sumários, prefácios e textos introdutórios de obras da história da psicologia publicados no Brasil, Gomes e da Silva Alencastro (2011) apontam que a maior parte das publicações com este tipo de conteúdo tem origem norte-americana. Estes materiais apresentam acontecimentos da história da psicologia relevantes para a formação da psicologia naquele país, negligenciando elementos importantes para a constituição da psicologia brasileira.

Uma busca por figuras francófonas no índice onomástico da obra História da Psicologia Moderna (SCHULTZ; SCHULTZ, 2015), uma das mais vendidas e utilizadas no Brasil, mostra que nomes citados até aqui, como Dumas, Ribot, Claparède, Esquirol, Morel, Georget, Ombredane e Souriau não recebem nenhuma menção. A Pinel são dedicados dois parágrafos (SCHULTZ; SCHULTZ, 2015, p.286). Piaget, descrito como caçador de caracóis e amante de pão com alho, aparece como "influência anterior da psicologia cognitiva" ao longo de três parágrafos (SCHULTZ; SCHULTZ, 2015, p.352-353), além de numa breve menção na página 359. Já Pierre Janet aparece duas vezes, a primeira numa lista de visitantes da Feira Comercial de Louisiana (p. 160), a segunda como estudioso dos sonhos (p.290). Binet é mais citado, em breves passagens (p. 85, 191, 290, 352) e numa seção, junto de Louis Terman, sobre o movimento dos testes psicológicos (p.165-167). Simon, famoso colaborador de Binet, aparece junto do amigo (p.166) e como professor de Piaget (p.352). Jacques Lacan, psicanalista cujas ideias circulam fortemente no Brasil, também não é citado na famosa obra do casal Schultz. 
De forma semelhante, observa-se que o manual norte-americano de Goodwin (2005) também traz poucas menções à psicologia francófona. A análise do índice onomástico indica que Dumas, Ribot, Claparède, Esquirol, Morel, Georget, Ombredane e Souriau não recebem nenhuma menção. Pinel aparece citado em uma seção de duas páginas sobre saúde mental. A epistemologia genética de Jean Piaget também recebe duas páginas de atenção, numa seção dedicada à psicologia do desenvolvimento. A grande exceção é a atenção dada a Binet, cuja escala e modelo de avaliação psicológica recebem uma seção, além de breves menções em outros trechos do livro.

Note-se que não se trata de acusar os autores de negligência, mas sim de indicar que a história da psicologia brasileira não é contemplada numa das obras mais relevantes na formação dos profissionais, pois foi desenvolvida para outro contexto, com preocupações distintas daquelas que caracterizam a formação em psicologia no Brasil. Assim, por conta desta circunstância, a relevância da matriz francesa é conhecida e reconhecida principalmente entre os especialistas no campo da história da psicologia.

A ausência, contudo, não é total. Gomes (2011) cita duas traduções de manuais de psicologia escritos por franceses publicados no Brasil em meados do século XX, sendo eles o Manual de Psicologia, de Paul Guillaume, que teve sua primeira edição aqui em 1956, e A Psicologia Contemporânea, de Paul Foulquié e Gérard Deledalle, publicado em 1969 que, em meio à dominância de manuais norte-americanos, indicam que havia algum interesse ou demanda editorial no Brasil por uma produção em psicologia geral ou história da psicologia abordada sob um ponto de vista dos autores francófonos. Em Portugal, algo semelhante ocorreu, considerando a publicação da história da psicologia dos franceses Braunstein e Pewzner, com bastante material francófono.

No universo dos manuais brasileiros, destaca-se a obra História da Psicologia: rumos e percursos (JACÓ-VILELA et al., 2015), onde podemos observar tratamento inteiramente diverso do encontrado no manual norte-americano já citado. A análise do índice onomástico da obra indica seis menções a Dumas, nove a Ribot, uma a Ombredane, uma a Souriau, nove a Pierre Janet, duas a Simon, dez a Lacan, 18 a Binet, 20 a Claparède e 25 a Piaget. Apesar de não serem citados Esquirol, Morel ou Georget, Pinel aparece três vezes. Além das menções, a obra conta com dois capítulos dedicados principalmente a pensadores da matriz francófona.

A obra de Jacó-Vilela, Ferreira e Portugal (2015), em conjunto com os diferentes verbetes e menções à matriz no Dicionário Biográfico da Psicologia no Brasil: pioneiros, 
organizado por Regina Helena de Freitas Campos (2001) indicam não apenas o interesse nestes autores francófonos, mas também sua relevância. O presente trabalho une-se aos esforços empreendidos por estes diferentes autores no aprofundamento dos conhecimentos sobre elementos relevantes da psicologia de matriz francófona em língua portuguesa.

Este texto tem por objetivo apresentar elementos da história da psicologia francófona do final do século XIX e início do século XX ausentes ou pouco citados na literatura sobre história da psicologia publicada no Brasil, o que poderá nos proporcionar informações para compreensão de nossa própria psicologia. O período abordado é também de importantes mudanças sociais e políticas nas terras franco-falantes, principalmente o início da Terceira República Francesa (1870-1940), marcado pelo liberalismo e laicismo. Também se observou no período em tela um grande desenvolvimento científico e tecnológico na França, concernente aos resultados da Guerra Franco-Prussiana. Assim, esta é uma fase de importantes reformas universitárias, com a difusão de novas correntes e movimentos epistemológicos importados de outros países (BROOKS, 1993), com a psicologia francófona passando por diversas mudanças, articulando-se com os discursos e saberes deste contexto (VICENTI, 2019).

\section{Materiais e métodos}

Para abordar este momento histórico da psicologia de matriz francófona e atingir os objetivos propostos, escolheu-se a construção do perfil de alguns dos mais importantes personagens da psicologia francófona da época, numa abordagem que pode ser denominada biográfica. Este trabalho traça um caminho bastante semelhante ao método já utilizado por Broussolle, Poirier, Clarac e Barbara (2012), e consagrado de maneira extensa pela obra de Campos (2001). Assim, após uma breve explanação do contexto histórico que marca o período destacado, são apresentados perfis de pensamento e atuação de cinco personagens da psicologia francesa.

Os autores escolhidos para a composição deste são: Paul Alexandre René Janet (18231899), importante representante de uma vertente em psicologia que surgiu nas fileiras da filosofia espiritualista de Victor Cousin (FOULQUIÉ; DELEDALLE, 1977); ThéoduleArmand Ribot (1839-1916), considerado fundador da psicologia experimental francesa e com relevante atuação para seu desenvolvimento (NICOLAS, 2002); Henri-Étienne Beaunis (18301921), mentor e diretor do primeiro laboratório de psicologia experimental na França e um dos primeiros estudiosos da psicofísica naquele país (NICOLAS; FERRAND, 2002); Alfred Binet 
(1857-1911), segundo diretor do primeiro laboratório de psicologia experimental na França e um dos criadores da Escala Binet-Simon (NICOLAS; SANITIOSO, 2011); e Pierre Marie Félix Janet (1859-1947), diretor de um laboratório em psicologia fisiológica na Salpêtrière e destacado estudioso das psicopatologias através de sua sistematização dos processos psíquicos (BROOKS, 1993);.

Foram escolhidos para pesquisa apenas autores franceses, pois sobre os dois autores suíços citados, Claparède e Piaget, já há vasta literatura publicada no Brasil. Contudo, personagens e acontecimentos relevantes da Suíça e Bélgica, parte da psicologia francófona e cuja importância também foi pouco apresentada no Brasil, deverão ser objeto de outros estudos e trabalhos.

Foram excluídos autores cuja obra se desenvolveu principalmente ou majoritariamente no século XX, sendo Pierre Janet uma exceção, pois suas contribuições no século anterior também são muito extensas e relevantes. Binet, apesar de ter ficado conhecido por seu trabalho nas primeiras décadas do século XX, desenvolveu a grande parte de sua obra no século XIX. Broca, Charcot e uma série de outros psiquiatras francófonos também foram excluídos por se considerar que sua produção tem especificidades que os aproximam da psiquiatria e da medicina, de modo que, apesar de seu pertencimento ao que se está denominando psicologia francófona, exigiriam um tipo de levantamento que deverá ser realizado em outros trabalhos.

A escolha dos cinco personagens foi feita principalmente em sua capacidade de representatividade do período estudado. Sua relevância e articulações mútuas permitem o entrelaçamento de suas narrativas com as de outros atores e eventos desse período. Assim, por meio dos autores escolhidos, foi possível a apresentação de contextos importantes para o desenvolvimento da psicologia francófona, com os quais eles estabeleceram ricas e diversas relações. A pequena lista de sugestões de autores francófonos fornecida por Penna (1992) também serviu de referência para a escolha dos nomes.

\section{Paul Janet e a psicologia dentro do espiritualismo eclético}

Paul Alexandre René Janet nasceu em 1823 em Paris, em uma família de boa posição socioeconômica, condição que permitiu ao jovem Paul ter um bom ambiente para seu desenvolvimento artístico e acadêmico (BOUTROUX, 1900). Seu avô paterno era proprietário de uma livraria e um pequeno teatro, bens que Paul Janet desfrutou durante sua infância (BOUTROUX, 1900). 
A morte de seu pai durante a revolução liberal de 1830, quando Paul contava com 9 anos, mudou a vida do jovem, que sai da casa de seu avô para morar em uma pensão (PICOT, 1903). Ele continua seus estudos frequentando o Collège Saint-Louis, numa rotina que define posteriormente como "odiosa" e de "encarceramento", que o ressente de sua família (PICOT, 1903). Nesse ínterim, ele se interessa pelos estudos em latim, principalmente por poesia. Posteriormente, inspirado pela figura de um professor de filosofia, despertou sua curiosidade e amor por esta área (PICOT, 1903).

Aos dezoito anos, após o término dos primeiros estudos, ele ingressa na École Normale Supérieure de Paris, visando desenvolver seus estudos filosóficos. No local, entrou em contato com ideias de diversos pensadores, como Maine de Biran (1766-1824) - autor conhecido por suas ideias sobre a introspecção e a consciência (BOUTROUX, 1900; FOULQUIÉ; DELEDALLE, 1977). Durante seu tempo na instituição, Paul Janet despertou o interesse de Victor Cousin (1792-1867), fundador da filosofia espiritualista eclética francesa, que o classificou como um pensador de primeira linha. Cousin tinha para com Paul Janet boas expectativas sobre seu futuro, conforme uma carta enviada ao Ministre de l'Instruction publique (BOUTROUX, 1900), equivalente a ministro da educação (BOUTROUX, 1900).

Paul Janet aceitou um convite de Cousin e, em 1845, tornou-se seu secretário (BOUTROUX, 1900). Atuando ao seu lado, Janet conheceu mais profundamente as ideias da filosofia espiritualista eclética de seu tutor - uma perspectiva voltada para a conciliação entre as escolas idealistas e empiristas, também sendo uma defensora de um renascimento da metafísica (FOULQUIÉ; DELEDALLE, 1977). Paul Janet colaborou com Cousin na produção da obra Du Vrai, du Beau et du Bien, resultado das conversas durante caminhadas pelos jardins de Paris, o que revela a próxima relação entre ambos (PICOT, 1903).

Após um ano trabalhando como secretário, Paul Janet foi convidado a ocupar um cargo de professor no Collège Royal de Bourges, dando seus primeiros passos como docente. No Collège, conforme Picot (1903), Janet encontrou colegas de espírito revolucionário e politicamente ativos, o que pode ter contribuído para que Paul começasse a pensar na filosofia articulada com os problemas práticos da vida e sua conexão com a realidade. Também naquela instituição, teve a oportunidade de se aprofundar nas ideias do sistema kantiano (BOUTROUX, 1900).

Em 1848, ele abandona seu cargo no Collège para ocupar uma cadeira na renomada Faculté de Strasbourg. Vicenti (2019) afirma que, durante esse período e motivado pela 
curiosidade, Paul Janet vai até um asilo da cidade francesa de Stéphansfeld, onde estuda por conta própria as faculdades psicológicas dos internos. A atividade de teorizar sobre as o assunto era comum entre os filósofos franceses da primeira metade do século XIX, como mostram os exemplos de Théodore Jouffroy e o próprio mestre de Paul Janet, Victor Cousin (NICOLAS, 2002).

A partir de suas observações coletadas no local ele publica, em 1857, um artigo, abordando o tratamento da loucura na Revue des Deux Mondes. Seu progressivo interesse neste campo o leva a ingressar, no ano seguinte, na recém-criada Société Médico-Psychologique em Paris (VICENTI, 2019). Paul Janet também tem, em seguida, algumas de suas obras filosóficas condecoradas pela Académie des sciences morales et politiques (BOUTROUX, 1900): Historie de la philosophique morale et politique (1858) - obra de cunho histórico sobre a moral e política, partindo da filosofia grega -, em 1859, e Philosophie du Bonheur (1863) - obra acerca da filosofia da felicidade -, nobilitada no seu ano de publicação.

Durante a Segunda República Francesa (1848-1852) a filosofia é retirada dos currículos franceses, sendo substituída pela lógica. Por influência de Cousin, o ensino de filosofia passou a ser associado à monarquia e sua "filosofia oficial", o espiritualismo eclético (GUILHON, 2013). Com o fim da Segunda República e o início do Segundo Império de Napoleão III, são realizadas diversas reformas universitárias e Victor Duruy, Ministre de l'Instruction Publique, estabelece novamente o ensino de filosofia de modo que, em 1863, Janet foi um dos responsáveis pela reconstrução de seu programa no país. Nesta ocasião inseriu conteúdos denominados psicológicos, como a consciência, sensações, sentidos e sentimentos, conforme programa anterior, de 1832 (NICOLAS, 2002).

$\mathrm{O}$ ano de 1864 foi muito relevante para Janet. Primeiro, é convidado para ocupar a cadeira de História da Filosofia na Sorbonne. Além disso, associa-se à Académie des Sciences Morales et Politiques, ambas grandes representantes da filosofia espiritualista francesa (NICOLAS, 2002). O momento era singular, pois esta filosofia vinha, desde a metade do século, sofrendo ataques e forte oposição de adeptos das doutrinas materialistas em ascensão, como o evolucionismo inglês e o positivismo de Auguste Comte (NICOLAS, 2002). As acusações destas correntes voltavam-se, principalmente, às ideias de cunho "metafísico" do espiritualismo, as rebaixando a meras produções literárias, incluindo aí os tratados psicológicos pensados a partir desses pressupostos, de autores como Adolphe Garnier e Adolphe Franck (NICOLAS, 2002; FOULQUIÉ; DELEDALLE, 1977). 
Janet, ao assumir a cadeira na Sorbonne, adota uma postura de defesa e validação do espiritualismo (BOUTROUX, 1900). Argumenta que a reflexão e a introspecção eram métodos válidos de produção de conhecimento, tal qual os métodos, pretensamente científicos, utilizados por seus opositores. Sobre este debate, Janet publica La Crise philosophique em 1865.

O filósofo, contudo, não se restringe aos métodos filosóficos limitados à introspecção. Como aponta Vicenti (2019), em 1866 ele publica um artigo sobre a obra de Claude Bernard: Introduction à la médecine expérimentale, revelando seu interesse pelos métodos experimentais da medicina, de modo que dialogassem com seus pressupostos filosóficos. Nicolas (2002) aponta que esta relação entre os dois campos não era inédita no país, pois Pinel já havia apontado neste sentido com sua Nosographie Philosophique. Apoiando-se neles, Janet acreditava ter encontrado uma conciliação entre os princípios científicos e metafísicos.

Considerando ser Janet um representante do espiritualismo, sua postura de diálogo com os métodos experimentais permitiu que elaborasse críticas à sua própria escola original. Ele considerava que certas posturas de seus colegas espiritualistas eram "ontologicamente drásticas", pois negligenciavam as pesquisas experimentais que já haviam sido realizadas (VICENTI, 2019). Este diálogo que Janet estabeleceu com a medicina experimental pode representar sua busca por uma base mais sólida para a psicologia espiritualista, de modo que encontrasse e se baseasse também em métodos que fossem considerados científicos.

Seguindo essa linha, Paul Janet publica, em 1867, Le Cerveau et la Pensée, obra em que defende o estudo da loucura através da observação objetiva como um meio para refletir sobre seus processos psicológicos subjetivos. Nela também critica o reducionismo feito pelos positivistas que abordavam a questão como uma mera variação fisiológica, realizando um grande reducionismo a uma única esfera materialista (VICENTI, 2019).

Durante o primeiro congresso de psiquiatria realizado em Paris ainda em 1867, tendo ele se tornado presidente da Société Médico-Psychologique, Janet faz um pronunciamento afirmando a existência de duas psicologias (VICENTI, 2019): uma filosófica, baseada na experiência interna e subjetiva; e uma médica, baseada na observação externa e na objetividade. Esse pronunciamento sintetiza a configuração do campo da psicologia francesa da época.

Durante as décadas de 1870 e 1880, observa-se um aumento do interesse na hipnose, sonambulismo provocado, histeria, inconsciência, entre outros assuntos, debate muito forte tanto nos meios acadêmicos quanto em outras esferas. Os médicos franceses se interessavam pela histeria desde a década de 1850, porém Charcot fora o responsável por renovar este campo 
de estudos, através da inserção da hipnose. A partir de então, Paris passa a ser um grande polo de estudo dos fenômenos inconscientes, atraindo pessoas de toda a França (CARROY, 2018; NICOLAS, 2002).

Os adeptos do espiritualismo não permaneceram à margem dessa tendência, entendendo que esses estudos poderiam representar uma ferramenta de experimentação e observação dos processos psicológicos. Acompanhavam atentamente os postulados científicos atribuídos a estes fenômenos na Salpêtrière, principalmente por meio do trabalho de Charcot, que teve, entre seus ilustres alunos, Paul Janet (VICENTI, 2019; CARROY, 2018).

Nicolas (2002) ressalta que já existiam muitos tratados psicológicos publicados dentro da filosofia até então, como o Traité des Facultés de l'âme de Adolphe Garnier, de 1852. Contudo, o cenário muda em 1873, quando Théodule Ribot publica o primeiro tratado psicológico científico da França, L'hérédité psychologique, que correspondia à sua tese de doutorado apresentada na Sorbonne. Paul Janet fez parte do comitê de avaliação da tese de Ribot, assumindo papel crítico da obra, não aprovando seu caráter determinista (BROOKS, 1993). Janet via no trabalho de Ribot uma representação do ultra-materialismo crescente, pois Ribot muitas vezes criticou, e ainda criticaria, a metafísica dentro da psicologia.

No período da defesa da tese de Ribot, a conjuntura política era propícia para a fomentação de uma psicologia científica. A França havia perdido a guerra franco-prussiana em 1871, e parte dessa derrota foi explicada pelo alto desenvolvimento científico da Prússia, país onde ocorrem grandes reformas universitárias que deram proeminência aos trabalhos laboratoriais, incluindo os psicofisiologistas. Como resultado disso, despertou-se um sentimento de atraso intelectual/tecnológico francês, que teve como resposta uma série de ações do governo para lidar com este problema (NICOLAS, 2002).

Nos anos seguintes à defesa, uma psicologia de caráter mais experimentalista se expandiu cada vez mais, concomitantemente à psicopatologia (NICOLAS, 2002). Ambas, psicopatologia e psicologia experimental, mantiveram pontos de interseção com o trabalho do próprio Ribot, que publicou obras sobre diversas psicopatologias neste período (GUILHON, 2013).

Essa psicologia construída com uma abordagem científica empregava técnicas de distanciamento do campo da metafísica e da subjetividade, introduzindo uma metodologia objetiva. Porém, para Paul Janet, não havia o abandono desta metafísica, mas sim um 
acabamento diferenciado para as mesmas questões tratadas pelos espiritualistas (BROOKS, 1993).

Levando isso em consideração, Brooks (1993) afirma que Janet foi um dos criadores do primeiro curso de psicologia experimental da Sorbonne, concretizado no início de 1885 e assumido por Ribot. Outro acontecimento que revela a articulação de Janet com esse movimento de objetivação da psicologia é o fato de ele ter se tornado membro, em 1885, da Société de psychologie physiologique, fundada por Ribot, Charcot e Richet, que tinha como objetivo a disseminação da psicologia científica (VICENTI, 2019).

Esta Sociedade foi responsável pela organização do primeiro Congresso Internacional de Psicologia em 1889, evento que teve, dentre suas características mais marcantes, sua diversidade (BROOKS, 1993; NICOLAS, 2002), e contou com a participação de Paul Janet (CARROY, 2018). Sua presença em meio a outras grandes figuras, como Helmholtz, Wundt, Bain, James e outros (NICOLAS, 2002), representa sua relevância no campo psicológico.

O ano de 1889 é também aquele em que Ribot abandona o curso na Sorbonne para ocupar uma cadeira no Collège de France (NICOLAS, 2020). Como nos revela Brooks (1993), Janet, reconhecendo a importância da continuidade do curso, foi o criador, novamente, de sua continuação por seu sobrinho Pierre Janet, somente em 1897 - a demora, de acordo com o autor, se deu por questões burocráticas e administrativas.

Paul Janet via em seu sobrinho um representante tanto da psicologia filosófica, por sua formação, capacidade reflexiva e de formulação de teorias psicológicas, quanto da psicologia científica e médica, exemplificadas pela sua tese filosófica L'automatisme psychologique e pelo fato de ele assumir um laboratório de psicologia experimental na Salpêtrière desde 1893 (BROOKS, 1993).

Já no fim de sua vida, Janet publica uma compilação de suas aulas de filosofia na Sorbonne, sob o título de Principes de Métaphisique et de Psychologie (1897). Em uma crítica sobre o livro, Bergson (1897) elogia a obra, atribuindo-a à capacidade de fomentar base sólida para a discussão dos múltiplos temas que aborda. Desta feita, o livro acabou sendo considerado como uma síntese de sua carreira intelectual. Paul Alexandre René Janet morreu em 1899.

No final, pode-se dizer que ele foi um importante representante da psicologia que residia dentro da filosofia espiritualista e eclética francesa, corrente fundamental para a compreensão da história da psicologia na França e seus inúmeros desdobramentos. Graças à sua postura, em certa medida diplomática entre as áreas do conhecimento, foi possível a formação e sustentação 
de um campo psicológico francês, onde diferentes ideias e projetos psicológicos floresceram. Paul Janet também fez jus à alcunha de eclético, porque nesse período em que a filosofia, psicologia, medicina, psiquiatria e fisiologia eram difíceis de serem delimitadas e separadas uma das outras, pode-se atestar, através de sua presença em diversas dessas áreas, sua relevância para a história da psicologia francesa da virada do século XIX para o XX. Paul Janet teve uma atuação que, aos olhos contemporâneos, poderia parecer inviável dada a sua presença em áreas tão distintas, mas seus movimentos em diferentes círculos contribuíram para a consolidação dos diferentes campos por onde esteve na França, movimentos e correntes que posteriormente circularam entre os intelectuais brasileiros do início do século XX..

\section{Théodule Ribot e a psicologia experimental.}

Théodule Armand Ribot nasceu em 1839 na cidade de Guingamp. Seu pai era um farmacêutico e sua mãe era proprietária da província de Pontrieux, na região da Bretanha. Nicolas e Murray (2000) apontam que nada muito relevante pode ser dito sobre sua infância, e que o garoto, ao terminar seus estudos básicos, foi para o liceu de Saint-Brieuc dos 15 aos 18 anos de idade. Mesmo com o interesse em prosseguir seus estudos, foi obrigado por seu pai a trabalhar até atingir a maioridade, à época 21 anos, quando largou o emprego e começou a se preparar para a seleção da École Normale Supérieure, instituição pública de ensino superior de grande prestígio.

Sua entrada na École se deu na segunda tentativa, em 1862, e lá Ribot teve contato com professores e colegas que o apresentaram a ideais como o da objetividade científica, conhecendo as proposições críticas à filosofia cousiniana, e teve ingresso nos estudos sobre as patologias (NICOLAS; MURRAY, 2000). A formação na instituição, que foi concluída em 1863, não garantia o direito de assumir seu almejado cargo de docente em algum dos liceus deste período. Era necessário ainda submeter-se à prova de seleção para as vagas no ensino público, a agrégation, no seu caso, de filosofia.

É apenas em sua segunda tentativa, em 1866, que Ribot consegue a aprovação na agrégation, obtendo um cargo de titular no liceu de Versoul (GUILHON, 2013; NICOLAS; MURRAY, 2000). Em uma carta ao amigo Alfred Espinas, Ribot reclama sobre como o processo de seleção, cuja banca era formada majoritariamente por nomes da filosofia eclética e espiritualista, pouco avaliou sua competência de filósofo ou de professor, demarcando certas questões políticas e ideológicas (GUILHON, 2013). 
De acordo com Rodrigues (2014), em 1866 Ribot começou a estudar obras inglesas acerca do materialismo, evolucionismo e objetivismo, interessado no modo como abordavam a psicologia (NICOLAS; MURRAY, 2000). Sua obra La psychologie anglaise contemporaine, de 1870, é um compilado destes estudos, cuja publicação ampliou os horizontes de seus compatriotas em direção a uma outra psicologia, desenvolvida nos países vizinhos (NICOLAS; MURRAY, 2000).

Seu livro recebeu diversas críticas dos espiritualistas e também do clero, que via o materialismo, que caracterizava a obra, como uma espécie de negação de Deus e da metafísica transcendental. Por outro lado, ele recebeu elogios de vários autores, como Stuart Mill, Herbert Spencer e Hippolyte Taine (GUILHON, 2013) - outro autor que vinha difundindo as ideias britânicas no idioma francês (FOULQUIÉ; DELEDALLE, 1977).

Os anos seguintes foram muito conturbados para Ribot (NICOLAS; MURRAY 2000). O prédio do liceu onde trabalhava foi ocupado durante a guerra da França com a Prússia. Ademais, seu pai morre de varíola - o próprio Ribot lutava contra a doença -, além de seu embate constante contra a Igreja que, por conta de suas ideias e publicações, o perseguia. Esta conjuntura o leva a mudar-se para Paris no ano de 1872.

Uma vez na capital, Ribot almejava o título de doutor da Sorbonne (NICOLAS, 2002). Ele envia duas teses para a banca de avaliação em 1873, uma em latim e outra em francês, esta tendo por título L'Hérédité: étude psychologique. A tese apresentava o caminho científico e objetivo que acreditava ser o melhor para a psicologia. Durante a defesa recebeu fortes ataques da banca, mas obteve seu doutorado mesmo assim, se tornando autor da primeira tese em psicologia científica do país (NICOLAS, 2002).

Após o recebimento do título de doutor, há um aumento em sua produtividade, ramificando e estendendo seus interesses para outros campos (NICOLAS; MURRAY, 2000). Traduz obras de Spencer, publica um trabalho sobre Fechner e Wundt na Revue Scientifique apresentando assim seu interesse na psicologia alemã - e inicia seus estudos em medicina, sendo aluno de Claude Bernard e conhecendo Jean-Martin Charcot.

No ano de 1876, Ribot funda a Revue philosophique de la France et de l'étranger, revista que tinha entre seus principais pressupostos a liberdade e a diversidade em suas publicações. A revista se tornou um dos pilares de sustentação dessa nova psicologia em desenvolvimento no país (SOULIÉ, 2017), pois através dela abriu-se um espaço estruturado 
para a divulgação deste campo, incluindo as ideias do próprio fundador, que a dirigiu até o fim de sua vida (GUILHON, 2013).

Ribot, em 1879, publica La psychologie allemande contemporaine, onde discorre sobre as ideias de Johannes Müller, Johann Friedich Herbart, Gustav Theodor Fechner e, principalmente, Wilhelm Wundt, que ocupa a maior parte da obra (RODRIGUES, 2014).

Nas décadas de 1870 e 1880, a França passa por um importante aumento no interesse do tema da hipnose e histeria, tanto acadêmico quanto popular. Ribot, que já estava inserido no meio médico, também se interessou pelo assunto, vendo nele uma possibilidade de exercer uma psicologia experimental objetiva. Ribot acreditava em uma relação de continuidade entre o normal e o patológico (GUILHON, 2013) e, no início da década de 1880, publica obras sobre as psicopatologias da memória, vontade e personalidade (NICOLAS; MURRAY, 2000), embora, como nos revelam Foulquié e Deledalle (1977), ele nunca tivesse tido contato com qualquer interno de hospital ou asilo, construindo seus trabalhos principalmente a partir de fontes secundárias. Trata-se de uma época em que Ribot já tinha certo reconhecimento e importância dentro dos meios intelectuais da França. Em 1885, recebe um convite para ministrar um curso de psicologia experimental na Sorbonne. No mesmo ano, ele cria a Société de psychologie physiologique, com Charcot e Richet (VICENTI, 2019).

Nicolas e Murray (2000) retratam que sua estadia na Sorbonne não foi muito agradável, embora o curso fizesse certo sucesso. Ribot tinha certos atritos com alguns de seus colegas. Além disso, entendia que as aulas eram um trabalho cansativo e fadigoso, manifestando uma indisposição para conduzi-las, pois restava pouco tempo para que conduzisse outros projetos de seu interesse. Com isso em mente, desde 1887, ele mantém diálogo com o administrador do Collége de France, Ernest Renan, sobre a possibilidade de assumir um cargo no local (GUILHON, 2013).

Em 1888, com a aposentadoria do filósofo Adolphe Frank, a cadeira de Droit de la nature et des gens seria transformada em uma cadeira de psicologia experimental e comparada. Concorrendo à vaga, os dois principais nomes em questão eram Henri Joly, representante dos espiritualistas, e o próprio Théodule Ribot, representante da psicologia científica. A disputa teve grande visibilidade naquele momento (NICOLAS; MURRAY, 2000).

Apesar do voto do conselho favorável a Joly, Ribot vence a disputa através de uma interferência política de um ministro favorável ao avanço das correntes científicas nas terras francesas (NICOLAS, 2002). A transformação da cadeira também previa a construção de um 
laboratório. Contudo, Ribot não era este tipo de experimentalista (NICOLAS, 2002). Posteriormente, recebe uma carta de Henry Beaunis que, se apoiando no atraso francês em comparação aos laboratórios de psicologia alemães e americanos, defende a criação de um congênere francês, se oferecendo para dirigi-lo (NICOLAS; FERRAND, 2002). Contando com o apoio do governo, o laboratório foi criado em 1889 dentro das instalações da Sorbonne, e Beaunis é nomeado seu diretor. Posteriormente, Alfred Binet ingressa no laboratório, primeiro como assistente, depois como diretor.

$\mathrm{Na}$ década de 1890, Ribot começa a escrever sobre temas relativos ao afeto e aos sentimentos, porém destituindo-os da filosofia espiritualista que dominava o campo até então (GUILHON, 2013). As grandes produções deste período são La psychologie des sentiments (1896), Essai sur l'imagination créatrice (1900), La logique des sentiments (1905), e Essais sur les passions (1907).

Ribot, assim como Paul Janet, em 1899 se torna um membro da Académie des sciences morales et politiques (NICOLAS; MURRAY, 2000), espaço de grande prestígio dentro da academia francesa.

Com o avanço da idade, para Ribot, lecionar tornara-se uma atividade mais difícil e, como apontam Nicolas e Ferrand (2000), aos poucos ele fez um processo de passagem de sua cadeira no Collège para Pierre Janet, sobrinho de seu antigo "rival" acadêmico, Paul Janet. Este acaba por assumir o posto em 1901 com a saída de Ribot por questões de saúde. Théodule Ribot morre em 1916, aos 77 anos.

Em 1939, às vésperas da Segunda Guerra Mundial, Paris celebrou o jubileu da psicologia francesa (FOULQUIÉ; DELEDALLE, 1977). Este evento comemorou o centenário do nascimento de Ribot e da cinquentenária fundação de sua cadeira no Collège de France, reconhecendo sua importância para o desenvolvimento da psicologia científica no país. O episódio ilustra bem a relevância atribuída a Ribot, chamado de "pai da psicologia experimental francesa" por vários pesquisadores (NICOLAS, 2002).

Para encerrar, conclui-se dizendo que Ribot foi um grande divulgador da psicologia que recebia a alcunha de científica, embora não representasse a nossa concepção de cientista da atualidade, distante do caráter "experimental", assemelhando-se, com os olhos contemporâneos, mais a um teórico. Para além de seu papel na disseminação das ideias dessa psicologia na língua francesa, ele teve envolvimento chave em importantes marcos para a 
consolidação do campo, sendo um personagem fundamental para a história da psicologia francófona.

\section{Henri Beaunis e a psicologia fisiológica.}

Henri Beaunis nasceu em 1830, o primeiro dentre cinco filhos. Conforme Nicolas (1995), a mãe de Beaunis trabalhava na administração da cidade de Rouen, no noroeste da França. Por conta das revoluções burguesas do período, a família se mudava constantemente, de modo que os filhos acabavam por alternar temporadas entre diferentes pensões. Foi somente aos 13 anos que Henri Beaunis se estabeleceu em definitivo numa pensão em Rouen, iniciando seus estudos no collège da cidade.

Ele concluiu os estudos aos 19 anos, ganhando o título de bacharel em filosofia e ciências físicas (NICOLAS; FERRAND, 2002). Na sequência, ingressou na École Secondaire de Rouen, no curso de medicina, mas, acreditando que teria melhores oportunidades na capital, muda-se para Paris em 1850 (NICOLAS, 1995).

Na cidade, o jovem Beaunis se deparou com um novo estilo de vida, que o teria distraído de seus estudos. Ele muda-se então para a cidade de Rodez, no sul da França, onde a família mantinha uma residência, o que sugere uma mudança em suas perspectivas. Após três anos, ele ingressa na faculdade de medicina de Montpellier (NICOLAS, 1995), próxima a Rodez, recebendo o título de doutor em 1856 com a tese: L'habitude en général. Entretanto, já com 25 anos e descontente com a dependência dos subsídios parentais, decide ingressar na carreira militar, iniciando com a patente de Aide-major ainda no ano em que tornou-se doutor. Posteriormente é enviado em missão para a Argélia, de onde só retornaria em 1860 (NICOLAS, 1995).

Como nos apresentam Nicolas e Ferrand (2002), após mais um período de serviço militar, no ano de 1863 Beaunis é aprovado na agrégation de medicina da faculdade de Estrasburgo, na fronteira com a Alemanha, dentro da seção de ciências anatômicas e fisiológicas, tendo escrito uma tese sobre o sistema linfático. Após 3 anos de estágio regulamentar, apresenta um curso sobre fisiologia enquanto trabalha no hospital militar. A pedido de um professor, para fins didáticos, escreve com o amigo e discípulo Abel Bouchard um tratado sobre anatomia de nome Nouveaux éléments d'anatomie descriptive et d'embryologie (1868), obra que foi republicada e traduzida para outros idiomas (NICOLAS, 1995). 
Durante os próximos 3 anos, ele continuou seu trabalho como docente e como médico de ofício até que, em 1870, é deflagrada a guerra franco-prussiana. Sendo Beaunis um militar, responde o chamado do exército. Na biografia de Beaunis, Nicolas (1995) afirma que, devido à turbulência da guerra, o médico transitou entre diversos locais - incluindo um período como prisioneiro -, participando ativamente da guerra. Ao final do conflito, ocupa o cargo de médicochefe de ambulatório. Porém, além do gosto amargo para todos os franceses por conta da derrota do país no conflito, Beaunis ainda viu a cidade de Strasbourg ser devastada.

Logo após a guerra, um decreto foi emitido pelo governo francês em 1872, que transferia a faculdade de medicina de Estrasburgo para a Faculdade de Nancy, onde Beaunis recebe a cadeira de fisiologia (NICOLAS; FERRAND, 2002). Junto desta nova posição vinha um laboratório que, embora "rudimentar", o auxiliou em suas aulas, o que contribuiu para a construção de um novo e melhorado laboratório três anos depois (NICOLAS, 1995).

A primeira menção de Beaunis à psicologia fisiológica foi em 1876, quando compilou sua experiência letiva e nos laboratórios em sua obra Nouveaux éléments de physiologie humaine comprenant les principes de la physiologie comparée et de la physiologie générale, onde aborda, de um ponto de vista da fisiologia, temas como linguagem, vontade, consciência, entre outros (NICOLAS; FERRAND, 2002). Dentre suas referências, encontram-se autores como Carpenter, Muller e Fechner (NICOLAS, 1995).

Beaunis produz algumas publicações em revistas, como aquela fundada por Ribot - que em 1879 havia pedido a ele por materiais sobre anatomia - na medida em que ganhava renome enquanto professor lecionando, dentre outros temas, sobre as ideias de Claude Bernard.

Na década de 1880, Beaunis, sob a liderança de Bernheim, se alinhou com pesquisadores - naquela que viria a ser chamada de Escola de Nancy - que se opunham às ideias da Salpetrière acerca da hipnose, histeria, entre outros. Como aponta Carroy (2018), Beaunis era responsável pelo estudo fisiológico da hipnose na instituição, atuando em conjunto de Bernheim e seus estudos envolvendo os benefícios terapêuticos, e Jules Liegeois com a questão civil/judicial. Ao final, a equipe concluiu que a hipnose era real, tendo benefícios terapêuticos, mas que sobre ela realizava-se um grande espetáculo e exagero por parte de Charcot. Afirmaram também que a técnica pouco revelava sobre as psicopatologias.

Todos esses estudos resultaram na publicação de Le somnambulisme provoqué (1886), livro em que ele discorre sobre a sugestão e a hipnose, relacionando-as um estado cerebral próximo ao do sonambulismo, e defendendo seu uso para o estudo psicofisiológico (NICOLAS; 
FERRAND, 2002). Dessa forma, Beaunis figurou como um dos grandes nomes deste período no assunto.

Em 1888, Ribot vai para o Collège de France, onde recebe a oportunidade de estabelecer um laboratório de psicologia experimental que, como apresentado em seção anterior, não o interessava. É Beaunis que retoma essa proposta, a partir de uma carta a Ribot (NICOLAS; MURRAY, 2000). Vale destacar que Beaunis foi membro fundador da Société de psychologie physiologique, indicando uma aproximação com as ideias de Ribot (NICOLAS; FERRAND, 2002). O laboratório enfim é criado em 1889, vinculado a École Pratique de Hautes Études, se instalando dentro da Sorbonne. O local contou com a colaboração de Wundt, que forneceu uma lista completa de sua aparelhagem e fornecedores para equipar o laboratório, que ficaria sob direção de Beaunis. Ele participou, também em 1889, do primeiro Congresso Internacional de Psicologia (NICOLAS, 1995).

Nicolas e Sanitioso (2011) retratam um encontro de Beaunis e Binet numa estação de trem em 1891. Ambos haviam se envolvido nos embates entre a Salpetrière e a Escola de Nancy, mas colocaram suas diferenças de lado para colaborar no novo laboratório, após Binet ter feito um pedido para sua integração.

Em sequência, Binet e Beaunis estabeleceram uma produtiva relação, tendo seus trabalhos iniciais sido publicados nas revistas: Revue scientifique, Revue générale des sciences, Revue des Deux Mondes, entre outras (NICOLAS, 1995). Binet se torna co-diretor do laboratório em 1892 (NICOLAS; FERRAND, 2002). A revista L'Année Psychologique, criada em 1895, se torna o principal meio de divulgação dos trabalhos lá realizados (NICOLAS, 1995).

No mesmo ano de criação da revista, Beaunis passa a liderança do laboratório para Binet, se retirando por questões de saúde. Após seu afastamento do laboratório, Beaunis passa a se dedicar à poesia e à arte, falecendo em 1921, aos 91 anos (NICOLAS, 1995).

Beaunis era um fisiologista integrante de uma tradição mais próxima da psicofísica, e sua atuação nessa vertente foi vital para a fundação do primeiro laboratório de psicologia experimental na França. Nota-se, assim, que a abordagem inaugurada por Ribot não se converteu na experiência laboratorial francesa, que teve que buscar dentre os pesquisadores da própria França um representante próximo da psicologia laboratorial alemã. A narrativa historiográfica da psicologia francesa não privilegia as diferentes etapas da psicofísica, como acontece com Fechner e outros na história da psicologia da Alemanha, mas é por meio dela que 
estabelece um marco laboratorial, rejeitando, contudo, a constituição do laboratório como fundador de uma prática científica no campo da psicologia.

\section{Alfred Binet e a psicologia individual}

Alfred Binet nasceu em 1857 na cidade de Nice, fruto de um relacionamento entre uma artista e um médico (SIEGLER, 1992). Quando criança frequentou o liceu da cidade, porém, ao se mudar com a mãe para Paris, aos 12 anos, veio a completar seus primeiros estudos no liceu Louis-le-Grand, posteriormente se graduando em Direito, em 1878 (NICOLAS; SANITIOSO, 2011).

Mesmo formado na área, não encontrou sua vocação nos estudos da lei, mas sim nos estudos em psicologia, através do contato com os autores ingleses e alemães mencionados nos livros de Ribot. Em 1880, ele publicou seu primeiro artigo na Revue Philosophique de la France et de l'Étranger. Após 6 anos escreve seu primeiro livro, La psychologie du raisonnement, alinhado com a visão de Ribot sobre o campo (NICOLAS; SANITIOSO, 2011).

Ainda no início da década de 80, por intermédio de um amigo, Binet conhece o médico Charles Féré e, acompanhando-o, passa a frequentar a Salpêtrière, vindo a publicar, em 1887, Le magnétisme animal com ele, referente aos estudos sobre as psicopatologias e o hipnotismo em que ele se via imerso (NICOLAS, 2002). No ano seguinte, lança Études de Psychologie Expérimentale, abordando novamente os debates acerca da histeria e da hipnose, se aprofundando cada vez mais nesse campo, e ao mesmo tempo obtendo uma graduação ciências naturais (NICOLAS, 2002).

No início da década de 1890, ingressa no laboratório situado na Sorbonne, após ter feito um pedido por um cargo a Beaunis (NICOLAS; SANITIOSO, 2011). Nesse período iniciou-se uma fase de grande experimentação em sua vida, principalmente envolvendo os processos mentais superiores, construindo os alicerces para aquilo que, posteriormente, ele denominaria psicologia das diferenças individuais (SIEGLER, 1992).

Nicolas (1994) conta a história de um italiano chamado Jacques Inaudi, famoso por fazer imensos cálculos mentais, e que, em 1892, fora organizada uma comissão para o estudo de seu caso. Charcot fez parte desse grupo, convidando Binet para também integrá-lo, e juntos fizeram diversos experimentos com Inaudi, alguns dentro do próprio laboratório onde ele era preparador, o que rendeu-lhe diversas publicações. Nelas, conclui que a capacidade de Inaudi era fruto de uma prodigiosa memória, e não de uma grande inteligência matemática. 
O mesmo autor narra experimentos realizados por Binet com outro grande calculador chamado Périclès Diamandi, estabelecendo comparações entre ambos. Logo em sequência, continuou estudando outros grupos específicos de indivíduos, como jogadores de xadrez, artistas, adultos, crianças e outrem, estudos esses muitas vezes feitos de forma independente, ou com a colaboração de outras pessoas, como por exemplo Victor Henri, seu discípulo.

Ele se torna co-diretor do laboratório em 1892 e diretor em 1895, nesse ínterim, surgindo com a ideia de criar o L'Année Psychologique, através dos boletins de trabalho institucionais. A revista, que teve sua primeira edição em 1894, se tornou o principal meio de divulgação de seus trabalhos, recebendo, dois anos depois, seu projeto de psicologia individual (NICOLAS, 1995).

Depois do nascimento de suas filhas, em 1885 e 1887, fruto de seu casamento com Laure Balbiani em 1884, seu interesse acerca dos processos mentais superiores infantis se intensificam (ANDRIEU, 2011). Em 1890 ele publica um artigo sobre algumas investigações realizadas envolvendo crianças, sustenta durante anos um estudo de suas filhas enquanto elas cresciam, e entra na Société libre pour l'étude psychologique de l'enfant em 1899 (NICOLAS; SANITIOSO, 2011).

Visando uma possível carreira enquanto docente, em 1902 ele concorre a duas vagas de psicologia que haviam ficado disponíveis, a de Ribot no Collège de France, que ele perde para Pierre Janet, e a que Janet ocupava na Sorbonne antes de ir para o Collège, que ele disputa com George Dumas, perdendo novamente (NICOLAS; SANITIOSO, 2011; NICOLAS; LUDOVIC, 2000). Embora não tenha obtido sucesso nestas empreitadas, no campo dos estudos psicológicos infantis a situação era diferente, tendo Binet publicado o livro La Suggestibilité em 1900 - livro sobre a sugestibilidade infantil apontado como inovador ao pensar em uma psicologia aplicada (NICOLAS; SANITIOSO, 2011) -, e assumido enquanto presidente da sociedade dos estudos psicológicos infantis no mesmo ano em que sofre as derrotas (SIEGLER, 1992).

Em 1903, Binet lança Étude expérimentale de l'intelligence, tratando sobre os experimentos conduzidos com suas filhas dentro de sua casa, com o auxílio de uma aparelhagem de medida antropométrica de que dispunha - embora seu cunho fosse muito mais qualitativo -, analisando suas capacidades intelectuais, não de forma a estabelecer uma hierarquia valorativa entre as duas, mas destacando suas características individuais, sendo essa uma de suas maiores obras (NICOLAS; FERRAND, 2011). De acordo com Klein (2014), em L'éducation psychologique de l'instituteur (1904) e La psychologie et la pédagogie (1904), dois 
manuscritos redescobertos na época, Binet discorre sobre a importância do diálogo entre a psicologia e a pedagogia, valorizando as descobertas psicológicas infantis e apontando a necessidade da postura experimental para a educação, defendendo uma reforma dentro da pedagogia.

No mesmo artigo, o autor também diz sobre seus consecutivos esforços empreendidos nessa direção. Ele participou de um comitê ministerial para discutir meios de lidar com a educação de crianças "especiais" - período em que a França iniciava um processo de universalização da educação -, onde lhe foi pedido a produção de um livro sobre o tema, e a elaboração, com seu discípulo Théodore Simon, de um teste capaz de identificar crianças com defasagem em relação ao esperado para sua idade.

O teste teve sua primeira versão apresentada em um congresso internacional de psicologia realizado em Roma, no ano de 1905. Naquele mesmo ano, ele assume um laboratório de psicologia pedagógica, associado a uma escola, na rua Grange-aux-Belles em Paris, utilizado principalmente como um local de formação para instrutores voluntários. Ulteriormente, já no final de sua carreira e vida, publicou mais algumas obras circundando esse tema, como: Enfants Anormaux (1907), com a coautoria de Simon, e Idées modernes sur les enfants (1909), tendo morrido em 1911 antes de concluir seu livro Traité de psychologie (NICOLAS; SANITIOSO, 2011; KLEIN, 2014).

Alfred Binet, ao final de sua vida, contou com uma grande quantidade de trabalhos, muitos divulgados para além das fronteiras francesas, e alguns deles sendo considerados relevantes após mais de um século de suas publicações (NICOLAS, 2014). Ele fica marcado como um importante personagem para a história da psicologia nestas terras, realizando uma abordagem muito mais qualitativa da experimentação dos processos mentais superiores, destacando o papel da observação e da compreensão do indivíduo, do que instrumentalista, que privilegia as medições fisiológicas através da aparelhagem laboratorial (KLEIN, 2009); também, mas não menos importante, sendo um dos construtores do diálogo entre o campo psicológico e o pedagógico.

\section{Pierre Janet e sua psicologia médico-filosófica}

Pierre Janet nasceu em 1859 em Paris, em uma família de boa condição financeira, com muitos membros no meio acadêmico. Seu berço lhe permitiu frequentar o Collège Sainte-Barbe, um renomado liceu parisiense (GREGORY; ZANGWILL, 1987). Janet (1930) retrata, em sua 
autobiografia, uma tendência desde pequeno para os estudos das ciências naturais, relativa a seu interesse em botânica, também se vendo muito imerso na devoção religiosa. Durante a tentativa, segundo ele penosa, de pensar em uma conciliação entre estes campos, diz ter-se direcionado aos debates filosóficos.

Ele destaca que seu tio paterno, Paul Janet, foi muito importante para seu desenvolvimento acadêmico, introduzindo-o à postura eclética em relação aos campos do saber. Com a entrada de Pierre Janet na École Normale Supérieure dentro de filosofia, em 1879, seu tio apresenta-o ao professor de fisiologia da Sorbonne, Albert Dastre, que inicia o aluno em seu laboratório. Desta forma, Pierre Janet desenvolveu estudos simultaneamente nas ciências naturais e humanas, encontrando um diálogo entre elas dentro da psicologia. Ele aponta que autores como Théodore Jouffroy e Maine de Biran, despertaram seu interesse no campo (JANET, 1930).

Em 1882 torna-se professor de filosofia do liceu de Havre. Interessado nos mecanismos perceptivos durante os fenômenos de alucinação, recorre à ajuda do médico Joseph Gibert, entusiasta do magnetismo animal, que florescia à época na Normandia. Gibert, deslocando-o de seu interesse primordial, o conduz às pesquisas em parapsicologia, apresentando-lhe uma mulher chamada Léonie, supostamente capaz de exercer a clarividência, sugestão mental e hipnotismo à distância, com a qual Pierre Janet trabalhou durante os anos posteriores. Desta maneira, ingressou nos estudos dos fenômenos que envolviam o hipnotismo (GREGORY; ZANGWILL, 1987; JANET, 1930).

Em 1885, na recém fundada Société de psychologie physiologique, da qual Richet e Charcot estavam entre os fundadores (VICENTE, 2019), Pierre Janet apresenta seus estudos parapsicológicos, obtendo certa notoriedade. Para evitar o que considerava mau uso de suas ideias, o que ele retrata ter acontecido com seus estudos, passa a adotar um método de experimentação mais detalhado e rigoroso (JANET, 1930). Janet começa também a se atentar aos estudos das psicopatologias, iniciando seus estudos médicos com Jules Falret e Charcot, que o convida a assumir um laboratório de psicologia experimental na Salpêtrière, em 1889 (JANET, 1930; PEREIRA, 2008).

Estas investigações psicopatológicas influenciaram sua tese em filosofia, L'automatisme psychologique (1889), onde discorre sobre o funcionamento e organização dos processos psíquicos, abordando os casos de histeria e catalepsia como decorrentes de "ideias fixas inconscientes" e sua maneira autônoma de operação. Em sua tese médica L'etat mental 
des hystériques (1893), dando continuidade à sua tese anterior, desenvolve ainda mais suas ideias sobre as psicopatologias, relacionando-as a um certo enfraquecimento psíquico pertinente à perda da capacidade de síntese - atividade primordial do psiquismo segundo ele -, propondo o uso da hipnose como um método de psicoterapia (JANET, 1930; PEREIRA, 2008).

Seu trabalho no laboratório, que ele conduz até 1910, foi fundamental para o desenvolvimento de suas empreitadas nos estudos psicopatológicos. Na Salpêtrière entrou em contato com os mais variados casos, como quadros de fobias, tiques e obsessões, que são compilados em alguns artigos e, principalmente, nos livros Névroses et idées fixes (1898) e Les Obsessions Et La Psychasthénie (1903) (JANET, 1930).

Durante esse período, ele já estava bem avançado em suas ideias sobre o campo, como apontam Bühler e Heim (2001), contando com uma vasta publicação e utilizando-se de conceitos como complexos cognitivos-emocionais, síntese e desagregação para explicar o funcionamento dos processos psíquicos.

Desde 1895, Pierre Janet trabalhou como substituto de Ribot no Collège de France, dirigindo simultaneamente o curso de psicologia experimental na Sorbonne de 1897 até 1902, quando assume a cadeira de Ribot, após sua aposentadoria (NICOLAS; LUDOVIC, 2000). Nesse ínterim, ele foi requisitado, por parte de estudantes da Salpêtrière, a conduzir um curso sobre psicologia clínica, e ele o fez entre 1896 e 1897; porém, na tentativa de organizar suas ideias sobre a área para um quesito didático, se deu conta da existente defasagem de sua sistematização, contornando-a, em certa medida, por sua experiência docente (JANET, 1930).

Em 1904 ele funda, com George Dumas, o Journal de psychologie normal et pathologique, numa empreitada de construir uma rede mais sólida para os estudos médicopsicológicos (GREGORY; ZANGWILL, 1987). Prosseguindo, daí em diante, uma tentativa de fundamentar uma psicologia de aplicação prática, que ele via a necessidade de ser desenvolvida, através, por exemplo, da publicação em 1919, dos 3 volumes de Médications psychologiques e de todo seu período letivo no Collège, que termina em 1935 (GREGORY; ZANGWILL, 1987; JANET, 1930) .

Um episódio marcante em sua carreira, e que o acompanhou pelo resto da vida, ocorreu durante esse intervalo. Em um congresso internacional de medicina, em 1913, ele acusa Sigmund Freud de plagiar suas ideias (PEREIRA, 2008). Isso sucedeu, entre outros eventos, em uma publicação bem crítica, em 1919, onde Janet diz da similaridade entre conceitos seus com os do austríaco, como: psycho-analyse e sua analyse psychologique, catharsis e sua 
dissociation des idées fixes, e refoulement com seu rétrécissement de la conscience. Suas acusações não foram nem um pouco bem recebidas - envolvendo outros desdobramentos, dignos de um trabalho à parte -, e são apontadas como o motivo de sua reputação ter caído em certo declínio na França (CASSULO, 2019; BÜHLER; HEIM, 2001).

Deixando o embate de lado, suas contribuições não se limitaram ao desenvolvimento de uma psicologia médica, se tornando posteriormente, em 1929, presidente da Société MédicoPsychologique (PUIG-VERGES; SCHWEITZER, 2008), e sendo apontado como um de seus pioneiros na França por Bühler e Heim (2001). Ele também desenvolveu seu próprio projeto de psicologia, que ele chamou de Psychologie de la conduite.

Janet (1930) faz críticas ao behaviorismo, dizendo que uma psicologia que estudasse a conduta humana deveria dar mais atenção ao campo da consciência, e também dar conta de condutas mais complexas, como a reflexão e a crença. Após fazê-las, ele diz que sua Psychologie de la conduite é mais ampla que a teoria americana, levando essas questões em conta na tentativa de circundar a conduta. Ela é abordada em sua obra De l'angoisse à l'extase (1926), que tem a pretensão de sintetizar todas suas ideias e teorias (PEREIRA, 2008), e ele dedicou parte de suas últimas décadas de vida em sua disposição dela, tendo falecido em 1947.

Pierre Janet deu passos importantes para a articulação dos saberes psicológicos com uma aplicação clínica, escrevendo sobre formas de tratamento das psicopatologias, respaldado por suas teorias acerca do funcionamento do psiquismo. Ele pode ser visto tanto como um representante da psicologia filosófica quanto da psicologia experimental, em certa medida sucedendo Théodule Ribot e Paul Janet mutuamente. Este diálogo feito por ele entre essas duas psicologias, que foram rivais em certo momento, demonstra o quanto elas se complementavam na realidade.

Diferentemente dos outros autores abordados, que passaram suas vidas majoritariamente no século XIX, Janet viveu o suficiente para observar os múltiplos rumos e percursos que a psicologia francófona tomou no século XX. Ele é essa ponte entre estes dois períodos, na medida em que ele viu essa psicologia se desenvolver após acompanhar e participar de muitos marcos de sua consolidação, como a criação de diversas revistas, sociedades, congressos, cursos e laboratórios. 


\section{Considerações finais}

A psicologia francófona mostra-se muito relevante para compreender a formação da psicologia brasileira. Isso se deveu, principalmente, à presença da produção intelectual criada neste idioma, por muitas décadas falado e bem conhecido pelos intelectuais brasileiros. A presença da psicologia francófona nas terras brasileiras se deu por diversas formas, como a importação de livros, intercâmbios, cartas, visitas, traduções, imigrações, entre outros.

Mesmo com essa relevância, os materiais de formação básica em história da psicologia disponíveis no Brasil em geral excluem ou pouco tratam da psicologia francófona, pois foram desenvolvidos para outros contextos, principalmente norte-americano, país onde a presença desta psicologia se deu de modo bastante diferente. A notável exceção nesta seara, a obra de Jacó-Vilela, Ferreira e Portugal (2015), certamente é um alívio neste espaço ainda pouco ocupado. Assim, falta muito para que leitores de língua portuguesa tenham acesso a textos que elencam, explicam e esclarecem elementos de uma psicologia vital para o conhecimento da constituição dos saberes psi desenvolvidos no país.

Mesmo esta posição é temporária, pois fundamentar a presença da relevância história da psicologia francófona apenas nos manuais e outros materiais mencionados (SCHULTZ; SCHULTZ, 2015; GOODWIN, 2005; JACÓ-VILELA; FERREIRA; PORTUGAL, 2015; FOULQUIÉ; DELEDALLE, 1977; GUILLAUME, 1956; CAMPOS, 2011), não é suficiente para demonstrar este ponto, sendo necessário um levantamento empírico bem mais completo das referências bibliográficas e ementas das disciplinas ligadas a conteúdos de história da psicologia nos cursos de graduação em Psicologia brasileiros.

A tarefa de resgatar histórias e narrativas de personagens da psicologia francófona ainda é bastante longa, como revela a lista de autores que foram excluídos do presente trabalho. $\mathrm{O}$ exemplo de Brousselle et al. (2012) na apresentação de figuras relevantes é bem mais extenso do que aquele exposto neste artigo, o que sugere a necessidade de uma expansão do trabalho iniciado por esta investigação Uma perspectiva menos institucional da psicologia, abrangendo saberes psi frequentemente excluídos das análises, pode trazer ainda mais atores francófonos presentes na formação das psicologias brasileiras, expandindo em muito o alcance desta proposta de investigação.

Uma investigação histórica baseada na existência de uma psicologia francófona, nos moldes delineados na introdução deste trabalho, permite o ingresso de uma modalidade de interpretação histórica que corre o risco de constituir-se como mera colonização da psicologia 
brasileira pela francófona. Não existe uma mera introdução da psicologia francófona no Brasil, mas sim o uso frequente destes atores na composição das redes e arranjos das psicologias nacionais. Ressalta-se que, diante da falta de conhecimentos em língua portuguesa capazes de resgatar elementos essenciais de diversos atores francófonos, corre-se o risco de construção de narrativas que não conseguem incluir elementos relevantes oriundos dos contextos de produção dos saberes psi nos países francófonos.

Cada um dos 5 autores abordados representa um veio específico da psicologia francófona desse período, sendo eles: uma psicologia que existia dentro da filosofia espiritualista, uma psicologia com pretensões científicas importada de outros países europeus, uma psicologia laboratorial mais fisiológica, uma psicologia experimental de caráter mais qualitativo, e uma psicologia médica e filosófica. Eles foram utilizados para elucidar a configuração do campo na virada do século XIX para o XX, e contextualizar sobre questões importantes como: as interferências políticas para o desenvolvimento de uma psicologia científica, o papel dos laboratórios, a concepção de experimentação, a importância da filosofia espiritualista eclética, os estudos sobre as psicopatologias, e a importação das ideias inglesas e alemãs.

Em suma, conclui-se sobre o caráter plural dessa psicologia, ela que estabeleceu, de forma indissociável, diálogo com a filosofia, medicina, fisiologia e psiquiatria, havendo ali toda uma rede de contextos específicos, composta por articulações e oposições, que permitiram seu desenvolvimento e consolidação nestas terras.

As riquezas e sutilezas desse importante recorte histórico, obviamente, ultrapassam a alçada do presente trabalho, que tem como objetivo apenas sua apresentação. Resgatando o que foi dito de início, há ainda uma necessidade de uma maior abordagem histórica da psicologia francófona em nosso idioma, haja vista sua importância para o estudo da história da psicologia brasileira. Esta empreitada é produto dessa demanda, futuramente podendo ser continuada por nós e por outros.

\section{Referências}

ANDRIEU, Bernard. Genèse des types mentaux: des notes des tests familiaux d'Alfred Binet à L'étude expérimentale de l'intelligence. L'Année psychologique, v. 111, n. 3, p. 509$532,2011$.

ANTUNES, M. A. M. A psicologia no Brasil: leitura histórica sobre sua constituição. São Paulo: Unimarco Editora; Educ, 1999. 
BEAUNIS, H. Études physiologiques et psychologiques sur le somnambulisme provoqué. Paris: Baillière, 1886.

BEAUNIS, Henri Étienne. Nouveaux éléments de physiologie humaine comprenant les principes de la physiologie comparée et de la physiologie générale. Paris: Baillière, 1876.

BEAUNIS, Henri Étienne ; BOUCHARD, Abel. Nouveaux éléments d'anatomie descriptive et d'embryologie. Paris: Baillières et fils, 1868.

BEAUNIS, Henri-Étienne. De l'habitude en général: thèse présentée et publiquement soutenue à la faculté de médecine de Montpellier le 25 février 1856. Montpellier: Boehm, 1856. (Tese de Doutorado.)

BERGSON, Henri. Compte rendu des Principes de métaphysique et de psychologie de Paul Janet. Revue philosophique de la France et de l'étranger, v. 44, p. 526-551, 1897.

BINET, Alfred. Les idées modernes sur les enfants. Paris: Flammarion, 1909.

BINET, Alfred; SIMON, Théodore. Guide pour l'admission des enfants anormaux dans les classes de perfectionnement. Paris: Colin, 1907.

BINET, Alfred. L'étude expérimentale de l'intelligence. Paris: Schleicher frères \& cie, 1903.

BINET, Alfred. La suggestibilité. Paris: Schleicher, 1900.

BINET, Alfred. Etudes de psychologie expérimentale: le fétichisme dans l'amour, la vie psychique des micro-organismes, l'intensité des images mentales, le problème hypnotique, note sur l'écriture hystérique. Paris: Doin, 1888.

BINET, Alfred. Le magnétisme animal: avec figures dans le texte. Paris: Félix Alcan, 1887.

BINET, Alfred. La psychologie du raisonnement : recherches expérimentales par l'hypnotisme. Paris: Alcan, 1886.

BOUTROUX, Emille. Notice sur Paul Janet. 1'Annuaire de l'Association des anciens élèves de l'École Normale, p. --18, 1900.

BROOKS III, John I. Philosophy and psychology at the Sorbonne, 1885-1913. Journal of the History of the Behavioral Sciences, v. 29, n. 2, p. 123-145, 1993.

BROUSSOLLE, E. et al. Figures and institutions of the neurological sciences in Paris from 1800 to 1950. Part III: neurology. Revue neurologique, v. 168, n. 4, p. 301-320, 2012.

BÜHLER, K. E.; HEIM, G. Introduction générale à la psychopathologie et à la psychothérapie de Pierre Janet. Annales médico-psychologiques, revue psychiatrique, v.159, n.4, p. 261-272, mai, 2001.

CAMPOS, R. H. de F.; GOUVEA, M. C. S. de; GUIMARÃES, P. C. D. A recepção da obra de Binet e dos testes psicométricos no Brasil: contrafaces de uma história. Rev. bras. hist. educ. v. 14, n. 2, p. 215-242, maio/ago. 2014.

CAMPOS, R. H. de F.; NEPOMUCENO, D. M.; SILVA, D. L. da; FAZZI, E. H. Funcionalismo no Brasil: pioneiros. Em: MASSIMI, M. (Org.). História da psicologia no Brasil do século XX. São Paulo: EPU, 2004, p.175-198.

CAMPOS, R. H. de F. (Org.). Dicionário biográfico da psicologia no Brasil: pioneiros. Rio de Janeiro: Imago Ed.; Brasília, DF: CFP, 2001. 
CARROY, Jacqueline. Jeux d'écoles hypnotiques: Paris-Nancy fin de siècle. Revue d'histoire des sciences humaines, n. 32, p. 73-97, 2018.

CASSEMIRO, Maria de Fátima Pio; CAMPOS, Regina Helena de Freitas. Formação de Professores para a Educação Especial: propostas de Helena Antipoff e seus Colaboradores na Fazenda do Rosário nos Anos de 1960. Revista brasileira de educação especial, v. 25, n. 2, p. 337-354, 2019.

CASSULO, Gabriele .Freud meets Janet. Notes towards a psychology of the plural-ego. La Rivista di Psicoanalisi, v. 13, p.99-116, 2019.

CENTOFANTI, Rogério. Radecki e a Psicologia no Brasil. Psicologia: ciência e profissão, v. 3, n. 1, p. 2-50, 1982.

COUSIN, Victor. Du vrai, du beau et du bien. Paris : Didier, 1853.

ENGEL, Magali Gouveia. Os delírios da razão: médicos, loucos e hospícios (Rio de Janeiro, 1830-1930). Rio de Janeiro: Editora Fiocruz, 2001.

FÁVERO, M. de L. A. Faculdade Nacional de Filosofia: projeto ou trama universitária? Rio de Janeiro: Editora UFRJ, 1989.

FOUlQUIE, P.; DELEDALlE, G. A psicologia contemporânea. São Paulo: Companhia Editora Nacional, 1977.

GOODWIN, C. J. História da Psicologia Moderna. Trad. de Marta Rosas. 2. ed. São Paulo: Cultrix, 2005.

GARNIER, Adolphe. Traité des facultés de l'âme: comprenant l'histoire des principales théories psychologiques. Paris: Librairie de Hachette, 1852.

GOMES, William B.; DA SILVA ALENCASTRO, Luciano. Anotações de história da psicologia em sumários e prefácios dos manuais introdutórios. Memorandum: Memória e História em Psicologia, v. 21, p. 105-135, 2011.

GREGORY, Richard L.; ZANGWILL, Oliver Louis. Pierre Janet. Em: The Oxford companion to the mind. Oxford University Press, 1987. p. 397-399.

GUILHEN, Ana Cecília Villela. O problema do método na psicologia científica de Théodule Ribot. 2013. 101f. Dissertação (Mestrado em psicologia) - Instituto de Ciências Humanas, Universidade Federal de Juiz de Fora, Juiz de Fora,MG, 2013.

JACÓ-VILELA, A. M.; FERREIRA, A. A. L.; PORTUGAL, F. T. (Orgs.) História da psicologia: rumos e percursos. 3. ed., 2. reimpressão. Rio de Janeiro: Nau Editora, 2015.

JANET, Paul. Principes de métaphysique et de psychologie: leçons profesées à la Faculté des lettres de Paris, 1888-1894. Paris : C. Delagrave, 1897.

JANET, Paul. Le cerveau et la pensée. Paris: Baillière, 1867.

JANET, Paul. La méthode expérimentale et la physiologie. Revue des Deux Mondes (18291971), v. 62, n. 4, p. 908-936, 1866.

JANET, Paul Alexandre René. La crise philosophique: MM. Paris:Baillière et fils., 1865.

JANET, Paul. Philosophie du bonheur. Paris : M. Lévy, 1863.

JANET, Paul. Histoire de la philosophie morale et politique dans l'antiquité et les temps modernes. Paris : Librairie philosophique de Ladrange, 1858. 
JANET, Pierre. Pierre Janet. A history of psychology in autobiography, v. 1, p. 123-133, 1930.

JANET, Pierre. De l'angoisse à l'extase. Paris: Félix Alcan, 1926.

JANET, Pierre. Les médications psychologiques: études historiques, psychologiques et cliniques sur les méthodes de la psychothérapie. Paris: Félix Alcan, 1919.

JANET, Pierre; RAYMOND, Fulgence. Les obsessions et la psychasthénie. Paris: Félix Alcan, 1903.

JANET, Pierre; RAYMOND, Fulgence. Névroses et idées fixes. Paris: Félix Alcan, 1898.

JANET, Pierre. État mental des hystériques. Paris :Rueff, 1893.

JANET, Pierre. L'automatisme psychologique: essai de psychologie expérimentale sur les formes inférieures de l'activité humaine. Paris: Alcan, 1889.

KLEIN, Alexandre. L'éducation psychologique de l'instituteur : des relations de la psychologie à la pédagogie chez Alfred Binet, à partir d'un manuscrit inédit. Bulletin de psychologie, n. 2, p. 171-182, 2014.

KLEIN, Alexandre. La correspondance d'Alfred Binet avec Théodore Flournoy: témoignage inédit d'une collégiale amitié. Bulletin de psychologie, n. 3, p. 239-250, 2011.

KLEIN. Alexandre. La philosophie scientifique d'Alfred Binet. Revue d'histoire des sciences, v. 62 , n. 2, p. 373-393, 2009.

KUHN, Thomas. A estrutura das revoluções científicas. 3a. ed. São Paulo: Editora Perspectiva, 1994.

LEBLANC, André. The origins of the concept of dissociation: Paul Janet, his nephew Pierre, and the problem of post-hypnotic suggestion. History of Science, v. 39, n. 1, p. 57-69, 2001.

MELO, C. S. B. de. Légitimation, application et formation: les missions scientifiques françaises au Brésil dans le domaine de la psychologie (1908 - 1947). 2016. 375f. Tese (Doutorado em Histoire de les Sciences) - École des Hautes Études en Sciences Sociales, 2017.

NICOLAS, Serge; MURRAY, David J. Le fondateur de la Psychologie "scientifique" française: Théodule Ribot (1839-1916). Psychologie et histoire, v. 1, p. 1-42, 2000.

NICOLAS, Serge; SANITIOSO, Rasyid Bo. Alfred Binet and experimental psychology at the Sorbonne laboratory. History of Psychology, v. 15, n. 4, p. 328, 2012.

NICOLAS, Serge; FERRAND, Ludovic. La psychologie cognitive d'Alfred Binet. L'Année psychologique, v. 111, n. 1, p. 87-116, 2011.

NICOLAS, Serge; GRAS, Doriane; SEGUI, Juan. Alfred Binet et le laboratoire de Psychologie de la Sorbonne. L'Année psychologique, v. 111, n. 2, p. 291-325, 2011.

NICOLAS, Serge; SANITIOSO, Rasyid Bo. Alfred Binet (1857-1911): a biographical sketch. Psychology \& History/Psychologie \& Histoire, v. 12, p. 1-20, 2011.

NICOLAS, Serge; GOUNDEN, Yannick; LEVINE, Zachary. The memory of two great mental calculators: Charcot and Binet's neglected 1893 experiments. American Journal of Psychology, v. 124, n. 2, p. 235-242, 2011.

NICOLAS, S. Histoire de la psychologie française: naissance d'une nouvelle science. Paris: In press, 2002. 
NICOLAS, Serge; FERRAND, Ludovic. Henry Beaunis (1830-1921): a physiologist among psychologists. Journal of Medical Biography, v. 10, n. 1, p. 1-3, 2002.

NICOLAS, Serge; FERRAND, Ludovic. Pierre Janet au Collège de France (I). Psychologie et Histoire, v. 1, p. 131-150, 2000.

NICOLAS, Serge; SEGUI, Juan; LEFRAND, Ludovic. Les premières revues de psychologie: la place de L'Année Psychologique. L'Année psychologique, v. 100, n. 1, p. 71-110, 2000

NICOLAS, Serge. Henry Beaunis (1830-1921) directeur-fondateur du laboratoire de Psychologie physiologique de la Sorbonne. L'Année psychologique, v. 95, n. 2, p. 267291, 1995.

NICOLAS, Serge. La mémoire dans l'œuvre d'Alfred Binet (1857-1911). L'Année psychologique, v. 94, n. 2, p. 257-282, 1994.

NICOLAS, Serge. Théodule Ribot, la psychologie et l'évolutionnisme Em: Darwin au Collège de France [en ligne]. Paris : Collège de France, 2020 (généré le 27 avril 2020).

OLIVEIRA, Lucia Montechi Valladares de. Os primeiros tempos da psicanálise no Brasil e as teses pansexualistas na educação. Ágora, v.V, n.1, p.133-154, jan/jun 2002.

PAROT, F.; RICHELLE, M. Psychologues de langue française: autobiographies. Paris: Presses Universitaires de France, 1992.

PENNA, A. G. Etienne Souriau (1892-1979). Em: CAMPOS, R. H. de FREITAS (Org.). Dicionário biográfico da psicologia no Brasil: pioneiros. Rio de Janeiro: Imago Ed.; Brasília, DF: CFP, 2001, p.360-361.

PENNA, A. G.; MASIERO, A. L. Maurício Campos de Medeiros (1885-1966). Em: CAMPOS, R. H. de FREITAS (Org.). Dicionário biográfico da psicologia no Brasil: pioneiros. Rio de Janeiro: Imago Ed.; Brasília, DF: CFP, 2001, p.225-226.

PENNA, A. G. História da psicologia no Rio de Janeiro. Rio de Janeiro: Imago, 1992.

PEREIRA, Mário Eduardo Costa. Pierre Janet e os atos psíquicos inconscientes revelados pelo automatismo psíquico das histéricas. Revista Latinoamericana de Psicopatologia Fundamental, v. 11, n. 2, p. 301-309, 2008.

PICOT, Georges. Paul Janet: notice historique. Paris : Librairie Hachette et Cie, 1903.

PUIG-VERGES, N.; SCHWEITZER, M. G. De l'automatisme physiologique à l'automatisme psychopathologique chez Pierre Janet. Continuités et ruptures depuis la référence à Paul Janet jusqu'aux reformulations des neurosciences. Annales Médico-psychologiques, revue psychiatrique, v.116, n. 3, p.206-212, 2008.

RIBOT, Théodule. Essai sur les passions. Paris:Alcan, 1907.

RIBOT, Théodule. La logique des sentiments. Paris:Alcan, 1905.

RIBOT, Théodule. Essai sur l'imagination créatrice. Paris:Alcan, 1900.

RIBOT, Théodule. La psychologie des sentiments. Paris:Germer Bailliere et cie., 1896.

RIBOT, Théodule. La psychologie allemande contemporaine:(École expérimentale). Paris: Germer Bailliere et cie., 1879. 
RIBOT, Théodule. L'hérédité: étude psychologique sur ses phénomènes, ses lois, ses causes, ses conséquences. Paris : Ladrange, 1873.

RIBOT, T. A. La psychologie anglaise contemporaine. Paris Ladrange, 1870.

RODRIGUES, Laís Fernanda. A recepção de Wundt por Durkheim: modelos de excelência científica numa era de delimitações disciplinares. 2014. 91f. Dissertação (Mestrado em Arte, Cultura e Teoria Social) - Universidade Federal de São Paulo, 2014.

ROTA-JÚNIOR, C.; CIRINO, S. D.; GUTIERREZ, L. Medindo o que não se conhece: o conceito de inteligência no contexto educacional brasileiro nas décadas de 1920 e 1930. Memorandum, n.36, p.1-18, 2019.

SCHULTZ, D.; SCHULTZ, S. E. História da psicologia moderna. São Paulo: Cengage Learning, 2015. (Tradução da 10a edição norte-americana)

SIEGLER, Robert S. The other Alfred Binet. Developmental psychology, v. 28, n. 2, p. 179190, 1992.

SILVA, Emerson Correia da. As apropriações e representações de Édouard Claparède no Brasil (1928-1973). 2013. 185f. Tese (doutorado em Educação) - Faculdade de Filosofia e Ciências. Universidade Estadual Paulista "Júlio de Mesquita Filho", 2013.

SOULIÉ, Stéphan. Théodule Ribot, Revue philosophique de la France et de l'étranger. Revue d'histoire des sciences humaines, n. 31, p. 255-264, 2017.

VASCONCELOS, M. S. A difusão das ideias de Piaget no Brasil. São Paulo: Casa do Psicólogo, 1996.

VINCENTI, Denise. Experience and Experimentation: medicine, psychiatry and experimental psychology in Paul Janet. Perspectives on Science, v. 27, n. 5, p. 704-738, 2019.

Yuri Pereira Antunes Vieira Universidade Federal Fluminense

André Elias Morelli Ribeiro Universidade Federal Fluminense E-mail: andre.elias.morelli@gmail.com 